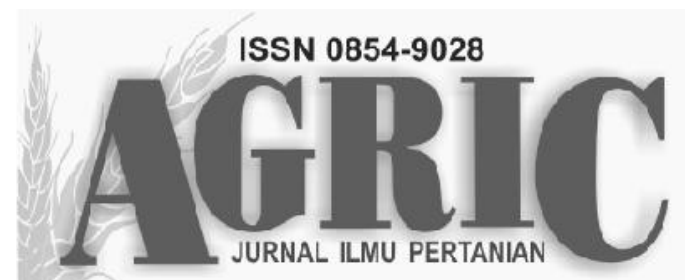

Fakultas Pertanian dan Bisnis Universitas Kristen Satya Wacana Jl. Diponegoro 52-60 SALATIGA 50711 - Telp. 0298-321212 ext 354 email: agric_fpb@yahoo.co.id, website: ejournal.uksw.edu/agric

\title{
EVALUASI VARIETAS PADI SAWAH PADA DISPLAY VARIETAS UNGGUL BARU (VUB) DI KABUPATEN KARAWANG, JAWA BARAT
}

\section{EVALUATION OF SOME RICE VARIETIES ON NEW VARIETY DISPLAY IN DISTRICT KARAWANG, WEST JAVA}

\author{
Wage Ratna Rohaeni \\ Balai Besar Penelitian Tanaman Padi, Balai Besar Tanaman Padi \\ Jl. 9. Sukamandi-Subang, Jawa Barat | Kode Pos 41256. Tel./Fax. +62 260 529751/+62 260529753 \\ e-mail:wagebptpjabar@gmail.com \\ M. Iskandar Ishaq \\ Balai Pengkajian Teknologi Pertanian Jawa Barat \\ Jl. Kayuambon No.80 Lembang Bandung Barat 40391| Telp. (022) 2786238 |Fax. (022) 2789846
}

Diterima 12 Maret 2015, disetujui 1 Juni 2015

\begin{abstract}
More than 80 high yielding varieties of rice have been released nationally by IAARD to support acceleration of national rice production. Inpari 13 was the one of some new variety that has been released at 2011 and have superior trait i.e early maturity and high yielding. Inpari 13 and some another new variety would disseminated at ICM program at this year. That variety needed to evaluated on Display Area and cultivated by using ICM technology and its compared with old variety as well as Ciherang. This study was to evaluate performance and yield of some new varieties compared old varieties specifically in Dem area. The experiment was conducted in West Java AIAT Dem Area, District Jayakerta, Karawang. The study was done on DS 2011 (Mei 2011-Januari 2012) by using randomized block design with 3 replications. Six varieties were tested i.e Ciherang, St. Bagendit, Inpari Inpari-7, Inpari-10, Silugunggo and Inpari-13. Integrated Crop Manajemen system i.e legowo 2:1, optimal fertilization, and IPM were used at this research. The results showed that there were signifant differences between varieties in all characters except leaf color index. Ciherang has the highest plant height $(97,59 \mathrm{~cm})$. Inpari-7 has the highest number of productive tillers and 100 grains weight (25 tillers/clump and 2,8 grams) and the least number of empty grains ( 7 grains/ panicle). St. Bagendit has the highest number of pithy grain (183 grains/panicle). Silugonggo was the early maturity but it's resistant to stems brown planthopper (almost had a crop failure). The highest dry grain harvest was owned by Situ Bagendit $\left(8,10\right.$ t.ha $\left.a^{-1}\right)$ followed Ciherang $\left(8,08\right.$ t.h $\left.a^{-1}\right)$,

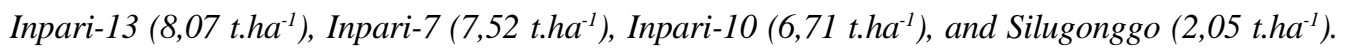

Keywords: varieties, performance, yield, Karawang 


\section{PENDAHULUAN}

Kurang lebih 80 varietas unggul baru padi telah dirilis secara nasional sebagai sumber daya genetik yang berperan penting terhadap P2BN (percepatan produksi beras nasional) maupun keberagaman varietas untuk perbenihan nasional. Varietas unggul yang masih menjadi favorit petani di Jawa Barat diantaranya Ciherang, Mekongga, Situ patenggang, dan Situ Bagendit baik karena aroma, kepulenan, dan poduktivitasnya yang bagus. Varietas unggul baru yang menjadi kandidat pengganti varietas unggul lama yaitu kelompok Inpari seperti Inpari-7, 10, dan 13.

Beragamnya varietas yang telah dilepas sangat berguna bagi pertanian. Varietas-varietas yang telah dirilis menjadi sumberdaya genetik yang akan menjadi pilihan bagi petani untuk menentukan varietas yang cocok untuk wilayahnya baik kondisi lingkungan abiotik maupun biotiknya. Ketersediaan varietas-varietas yang dapat menjadi pilihan, memudahkan petani untuk melakukan pergiliran varietas. Semakin banyak varietas yang berdaya hasil tinggi dan adaptasinya luas dapat memudahkan diseminasi varietas terutama untuk menunjang program pemerintah. Kementerian Pertanian (2009) menargetkan Indonesia mampu swasembada berkelanjutan mulai tahun 2010. Salah satu komponen teknologi yang sudah terbukti meningkatkan produksi hasil adalah penggunaan varietas unggul baru. Sebelumnya menurut Sumarno (2007), untuk mempertahankan dan meningkatkan ketahanan pangan nasional perlu aplikasi penataan pola dan pergiliran tanam baik pergiliran jenis tanaman maupun varietas, serta penanaman multi varietas adaptif spesifik lokasi dan musim.

Pada proses rilis varietas, pengujiannya tidak dilakukan secara merata di seluruh wilayah Indonesia. Untuk pelepasan varietas padi dibutuhkan pengujian terhadap minimal 7 lokasi dan 2 musim. Menurut Suhartini et al. (1997), padi termasuk tanaman yang mempunyai spektrumekologi yang relatif luas dan dibudidayakan di berbagai tipe agroekosistem. Setiap agroekosistem mempunyai masalah dan kendala yang berbeda, seperti keracunan kimia, kekeringan, suhu rendah, rawan hama dan penyakit tertentu. Oleh sebab itu penelitian ini penting dilakukan untuk mengetahui daya hasil pada lokasi-lokasi terutama wilayah yang menjadi lumbung padi nasional secara spesifik seperti Kabupaten Karawang.

Tujuan dari penelitian ini adalah untuk mengevaluasi keragaan varietas unggul baru (VUB) ada display di Dem Area petani pada kegiatan sekolah lapang pengelolaan tanaman terpadu (SL-PTT).

\section{MOTODE PENELITIAN}

Penelitian dilakukan di Dem Area yang merupakan tempat pelaksanaan pendampingan teknologi mendukung sekolah lapang pengelolaan tanaman (SL-PTT) terpadu di Kecamatan Jayakerta, Kabupaten Karawang. Penelitian dilaksanakan pada bulan Mei 2011 s.d Januari 2012. Rancangan yang digunakan adalah RKLT dengan ulangan 3 kali dan perlakuan sebanyak 6 varietas. Masingmasing petak percobaan seluas $2 \mathrm{~m}$ x $30 \mathrm{~m}$ sehingga luas areal kajian sekitar $1200 \mathrm{~m}^{2}$.

Varietas unggul baru yang diuji adalah Inpari-7, 10, dan 13. Varietas lama yang diuji yaitu Ciherang, St. Bagendit, dan Silugonggo. Sistem budidaya yang digunakan adalah sistem pengelolaan tanaman terpadu (PTT) yaitu cara tanam legowo 2:1, pemupukan secara optimal berdasarkan rekomendasi perangkat uji tanah sawah (PUTS), pengendalian hama secara pengelolaan hama terpadu (PHT).

Data pengamatan meliputi tinggi tanaman, jumlah anakan produktif/rumpun, umur berbunga, jumlah bulir bernas/malai, jumlah bulir hampa/malai, bagan warna daun (BWD), umur panen, persentase kadar air (KA), dan gabah kering panen (GKP) (ton/ha). Data lain sebagai penunjang adalah data serangan hama dan kondisi umum lahan.

Data hasil pengamatan diolah dengan analisis ragam. Analisis diproses dengan menggunakan SAS system 6 . Apabila berbeda nyata pada taraf 5 persen diuji lanjut dengan menggunakan uji Duncan.

\section{HASIL DAN PEMBAHASAN}

\section{Tingkat Serangan HPT Dominan dan Kondisi Umum Tanaman}

Hama penyakit tanaman (HPT) utama yang dominan menyerang adalah wereng batang coklat 
(WBC). Varietas Silugonggo mengalami serangan hama WBC yang cukup parah. Jumlah WBC mencapai 22 ekor/tanaman. Hal tersebut menyebabkan jumlah gabah hampa yang tinggi (28 gabah/rumpun) dan jumlah gabah bernas yang terbentuk menjadi berkurang ( 77 gabah isi/malai).

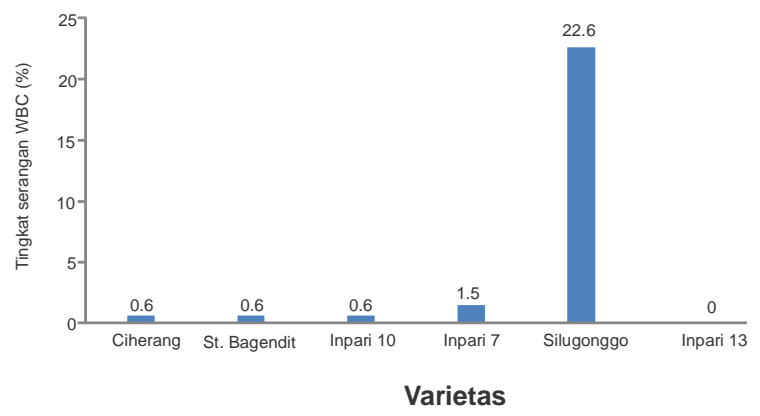

Gambar 1. Tingkat serangan WBC (\%) terhadap varietas yang diuji.

Berdasarkan Gambar 1, varietas Silugonggo tidak baik ditanam di wilayah Karawang. Varietas ini diserang WBC dengan tingkat serangan mencapai 22,6 persen. Dilain pihak, Inpari-13 sangat baik didiseminasikan di wilayah yang memiliki tingkat serangan hama wereng yang tinggi. Wereng coklat di Indonesia merupakan hama laten yang merusak tanaman padi sejak 1930 sampai sekarang. Menurut Effedi (2006) salah satu cara peningkatan produksi padi di lokasi yang merupakan endemik hama wereng adalah dengan cara menanam varietas tahan wereng. Hasil penelitiannya di Karawang pada MK 1995 menunjuk-

kan bahwa penerapan PHT dengan penanaman varietas tahan wereng meningkatkan hasil panen padi hingga 37 persen. Baehaki (2012) dan Baehaki (2013) menyatakan bahwa pengendalian hama yang paling ampuh adalah bertanam padi secara serentak.

\section{Analisis Ragam}

Keragaman antar varietas sudah mulai terlihat pada fase vegetatif. Secara umum dapat dilihat perbandingan visualisasi keragaan antar varietas mulai dari karakter tinggi tanaman, jumlah anakan, dan akar pada Gambar 2. Perbedaan tinggi tanaman dan akar dicerminkan dengan perbedaan tinggi visualiualisasi gambar. Varietas dengan tinggi tanaman tertinggi pada fase vegetatif dimiliki oleh Silogonggo $(65,5 \mathrm{~cm})$ namun varietas ini paling sedikit dari segi jumlah anakan. Varietas Situ Bagendit memiliki akar paling lebat dan jumlah anakan paling banyak (21 anakan).

Analisis ragam dilakukan pada data kuantitatif hasil pengamatan fase generatif. Berdasarkan analisis ragam pada Tabel 1, Terdapat keragaman sangat nyata antar varietas untuk semua karakter yang diamati kecuali indeks warna daun berdasarkan BWD. Berdasarkan Probability value yang kurang dari 0,01 , maka keragaman antar varietas pada karakter tinggi tanaman, jumlah anakan produktif, bobot 100 butir, bulir bernas per malai, dan bulir hampa per malai adalah berbeda sangat nyata.

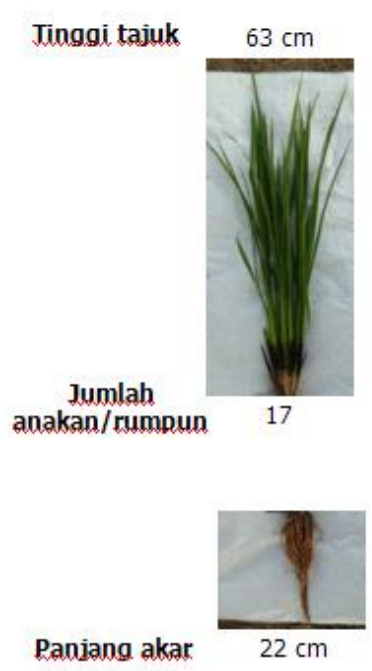

(a)

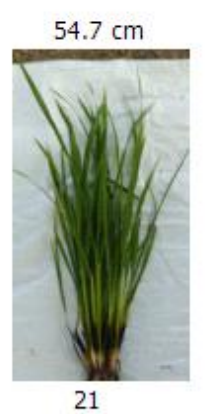

21

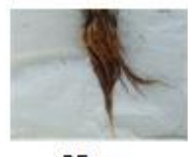

(b)

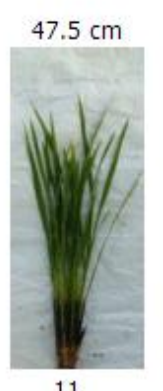

11

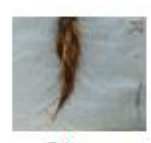

(c)

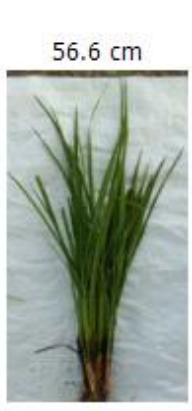

19

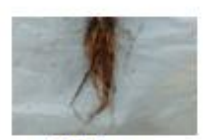

$22.3 \mathrm{~cm}$

(d)

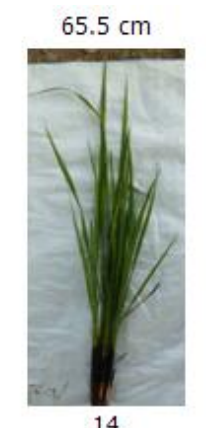

14

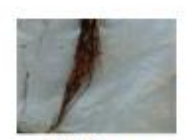

$22.1 \mathrm{~cm}$

(e)
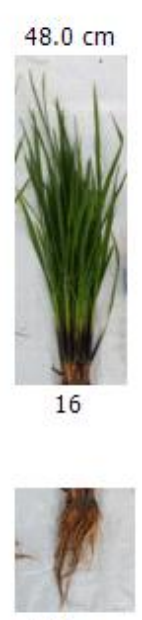

$24 \mathrm{~cm}$

(f)

Gambar 2. Keragaman tinggi tanaman dan akar pada fase vegetatif pada umur 23 HST (a): Ciherang, (b): St. Bagendit, (c): Inpari-10, (d): Inpari-7, (e): Silugonggo, (f): Inpari-13 
Uji lanjut Duncan menunjukkan bahwa karakter tinggi tanaman Ciherang adalah paling tinggi dibanding varietas lain $(97,59 \mathrm{~cm})$, sedangkan varietas Silugonggo memiliki keragaan paling pendek $(79,19 \mathrm{~cm})$ (Tabel 2). Sedangkan Inpari 7,10 , dan 13 memiliki tinggi tanaman yang sama (ditandai dengan huruf yang sama di belakang angka).

Karakter jumlah anakan produktif/rumpun paling tinggi dihasilkan oleh varietas Inpari-7 ( 25 anakan/rumpun). Varietas Ciherang memilki tinggi tanaman paling tinggi, namun dari segi jumlah anakan produktif paling rendah. Hal tersebut mengindikasikan bahwa keragaan tanaman yang tinggi tidak menjamin jumlah anakannya banyak. Berdasarkan beberapa penelitian menunjukkan bahwa nilai korelasi antara tinggi tanaman dan jumlah anakan produktif adalah rendah dan tidak nyata pada beberapa penelitian pada padi < 0,5 (Rohaeni $e t$ at., 2013; Pramudyawardhani, 2014).

Jumlah anakan produktif Inpari-7, 10 dan 13 tidak berbeda nyata yang ditunjukkan oleh huruf yang sama dibelakang angka. Begitupun dengan karakter tinggi tanaman. Meskipun demikian, dari tiga jenis inpari tersebut, Inpari-7 memiliki jumlah anakan produktif paling banyak.

Indeks hijau daun yang diukur berdasarkan BWD menunjukkan nilai yang tidak berbeda nyata antar varietas. Rentang warna antara 3,8 - 4,0 yang merupakan kriteria normal. Nilai BWD dipengaruhi oleh genetik tanaman itu sendiri atau tingkat kandungan $\mathrm{N}$ dalam tanah. Hasil-hasil penelitian BB Padi (2006) menunjukkan bahwa nilai BWD yang tidak berbeda nyata mengartikan warna daun tidak berbeda antar varietasnya. Warna daun adalah suatu indikator yang berguna bagi kebutuh- an pupuk $\mathrm{N}$ tanaman padi. Daun yang bewarna pucat atau hijau kekuningan menunjukkan bahwa tanaman kekurangan $\mathrm{N}$.

\section{Karakter Komponen Hasil dan Hasil (GKP)}

Uji lanjut terhadap karakter komponen hasil menunjukkan bahwa jumlah bulir bernas/malai tertinggi dihasilkan oleh varietas Situ Bagendit (183 bulir/malai). Jumlah bulir bernas varietas situbagendit sangat signifikan dibanding varietas lain. Situbagendit merupakan padi gogo yang sampai sekarang sudah dikenal dapat ditumbuhkan secara baik pada lahan sawah irigasi. Berdasarkan hasil kajian Setyorini et al. (2010), Situ Bagendit yang ditanam secara gogo rancah memiliki jumlah bulir bernas yang tidak berbeda nyata dengan varietas unggul lama (IR 64) dan mampu memberikan nilai produktivitas 3,93 ton/ ha pada musim kering $(<1000 \mathrm{~mm}$ per tahun dan bulan basah yang sangat singkat \pm 3 bulan).

Varietas lain yang memiliki jumlah bulir lebih dari 100 adalah varietas Ciherang (119 bulir/malai) dan Inpari-13 (155 bulir/malai). Dalam hal ini pengisian bulir padi paling optimal dihasilkan pada varietas Ciherang dengan persentase bulir bernas per malai yang paling tinggi dibandingkan varietas lainnya (92,71\%). Varietas Inpari-13 memiliki jumlah bulir bernas yang lebih tinggi dibanding Ciherang, namun persentase bulir bernas lebih rendah dibandingkan Ciherang.

Berdasarkan deskripsi varietas BB Padi (2015), Situ Bagendit memiliki daya adaptasi yang cukup baik pada kondisi tanah kering. Varietas ini tahan pada kondisi kekeringan (jenis padi gogo) dan baik ditumbuhkembangkan di lahan irigasi. Berbeda halnya dengan Situ Bagendit, Inpari-13 membutuhkan pasokan air yang cukup. Terlihat ketika

Tabel 1. Rekapitulasi analisis ragam karakter agronomi

\begin{tabular}{clccr}
\hline No. & Sumber Keragaman & F-hit & P-Value & Rata-rata \\
\hline 1 & Tinggi tanaman & $17.81^{* *}$ & 0.0001 & 88.07 \\
2 & Jumlah anakan produktif & $6.67 * *$ & 0.0056 & 21.77 \\
3 & Nilai BWD (bagan warna daun) & $0.69^{\text {tn }}$ & 0.6341 & 3.83 \\
4 & Bobot 100 butir & $210.66^{* *}$ & 0.0001 & 2.59 \\
5 & Bulir bernas/malai & $30.12^{* *}$ & 0.0001 & 118.83 \\
6 & Bulirhampa/malai & $16.55^{* *}$ & 0.0001 & 15.63 \\
\hline \multicolumn{2}{l}{ Keterangan $: * *=$ berbeda sangat nyata pada taraf $1 \%$, tn $=$ tidak berbeda nyata }
\end{tabular}


kondisi umum fase vegetatif terjadi kekurangan pasokan air, Inpari-13 mengalami hambatan pertumbuhan (jumlah anakan dan tinggi tanaman lebih kecil dibandingkan tanaman yang mendapatkan pasokan air yang cukup.

Karakter komponen hasil sangat menentukan hasil panen. Hasil penelitian Pang et al (1999), menunjukkan bahwa jumlah gabah/malai memberikan kontribusi terhadap hasil gabah. Dalam hal ini, Inpari-13 memiliki jumlah gabah rata-rata lebih tinggi dibanding Ciherang. Perbaikan kondisi lingkungan untuk meningkatkan optimalisasi pengisian bulir padi memungkinkan meningkatan kontribusi terhadap hasil. Penelitian Sutaryo et al. (2003) menunjukkan bahwa terdapat hubungan yang erat antar bobot 1000 butir dengan hasil pada padi sawah. Hubungan tersebut dipengaruhi secara tak langsung melalui malai terhadap hasil produksi.

Berdasarkan data Tabel 4, umur varietas padi yang diuji tergolong genjah. Ciherang memiliki umur panen 95 hari, Inpari-7, 10 dan 13 memiliki umur panen yang sama (90 hari), Situ Bagendit memiliki umur panen 88 hari dan Silugonggo 85 hari. Secara umum, umur panen menjadi lebih pendek. Hal tersebut diduga karena musim kering yang berkepanjangan selama musim tanam 2011. Suhu yang tinggi menyebabkan evapotranspirasi yang tinggi sehingga pemasakan bulir padi menjadi lebih cepat dan waktu panen menjadi maju.

Karakter hasil merupakan karakter paling penting untuk diketahui pada evaluasi beberapa varietas padi sawah yang dikaji. Hasil GKP menunjukkan bahwa Situ Bagendit adalah varietas dengan nilai
GKP paling tinggi $(8,10$ ton/ha) diikuti Ciherang (8,08 ton/ha). Inpari-13 yang merupakan varietas unggul baru yang diharapkan dapat menggantikan varietas-varietas lama seperti Ciherang masih memiliki GKP di bawah Ciherang. Keunggulan dari Inpari-13 pada penelitian ini adalah tingkat ketahanan terhadap serangan hama WBC. Petakpetak percobaan untuk varietas Inpari-13 tidak diserang oleh WBC sedangkan varietas lain mendapat serangan WBC.

Berdasarkan Gambar 1 sebelumnya, terlihat bahwa Inpari-13 tidak mendapat serangan hama WBC. Sehingga Inpari-13 berpotensi untuk dikembangkan di daerah endemik hama WBC, sedangkan varietas Silugonggo tidak dapat dikembangkan pada areal yang memiliki potensi adanya serangan WBC di lapang. Produktivitas Silugonggo yang sudah terkena serangan WBC hanya mencapai 2.05 ton/ha. Areal lahan penelitian sudah dalam kondisi sehomogen mungkin sehingga data serangan hama WBC dapat menjadi informasi tambahan yang dapat dikaji lebih lanjut mengenai ketahanan varietas-varietas tersebut terhadap hama WBC.

Varietas Ciherang dan Situbagendit memiliki keragaan yang masih bagus di Kabupaten Karawang. Nilai GKP 8,10 ton/ha untuk Situ Bagendit dan 8,08 ton/ha untuk Ciherang. Kelebihan 2 varietas tersebut dibanding Inpari-13 adalah dari segi rasa yang pulen dan aromatik. Berdasarkan Toha et al. (2008), Ciherang merupakan varietas padi sawah yang dapat dibudidayakan secara gogo, sebaliknya Situ Bagendit merupakan padi gogo yang dapat dibudidayakan di lahan sawah. Hasil panen Ciherang pada budidaya gogo setara dengan situ bagendit. Namun demikian, berdasarkan hasil

Tabel 2. Uji lanjut Duncan pada karakter tinggi tanaman, jumlah anakan produktif, dan BWD

\begin{tabular}{clrrrrrr}
\hline No. & Varietas & \multicolumn{2}{c}{ Tinggi tanaman } & \multicolumn{3}{c}{$\begin{array}{c}\text { Jumlah anakan } \\
\text { produktif }\end{array}$} & \multicolumn{2}{c}{ BWD } \\
\hline 1 & Ciherang & 97.59 & $\mathrm{a}$ & 18.87 & $\mathrm{c}$ & 3.8 & $\mathrm{a}$ \\
2 & St. Bagendit & 84.97 & $\mathrm{c}$ & 21.93 & $\mathrm{ab}$ & 3.8 & $\mathrm{a}$ \\
3 & Inpari-10 & 88.76 & $\mathrm{cb}$ & 23.00 & $\mathrm{a}$ & 4.0 & $\mathrm{a}$ \\
4 & Inpari-7 & 87.70 & $\mathrm{cb}$ & 24.73 & $\mathrm{a}$ & 3.8 & $\mathrm{a}$ \\
5 & Silugonggo & 79.19 & $\mathrm{~d}$ & 19.40 & $\mathrm{bc}$ & 4.0 & $\mathrm{a}$ \\
6 & Inpari-13 & 90.22 & $\mathrm{~b}$ & 22.67 & $\mathrm{a}$ & 3.6 & $\mathrm{a}$ \\
\hline
\end{tabular}

Keterangan: angka-angka yang diikuti oleh huruf yang berbeda menandakan perbedaan yang nyata 
Tabel 3. Uji lanjut Duncan pada karakter bobot 100 butir, bulir bernas/malai, dan bulir hampa/ malai

\begin{tabular}{|c|c|c|c|c|c|c|c|c|}
\hline \multirow{2}{*}{$\frac{\text { No. }}{1}$} & \multirow{2}{*}{$\begin{array}{c}\text { Varietas } \\
\text { Ciherang }\end{array}$} & \multicolumn{2}{|c|}{$\begin{array}{c}\text { Bobot } 100 \text { butir } \\
(\mathrm{g})\end{array}$} & $\begin{array}{c}\text { Bulir } \\
\text { bernas/malai }\end{array}$ & \multicolumn{2}{|c|}{$\begin{array}{c}\text { Bulir } \\
\text { hampa/malai }\end{array}$} & \multicolumn{2}{|c|}{$\begin{array}{c}\% \text { bulir } \\
\text { bernas/malai }\end{array}$} \\
\hline & & 2,55 & $\mathrm{c}$ & $119,6 \mathrm{c}$ & 9,4 & $\mathrm{c}$ & 92,71 & $\mathrm{c}$ \\
\hline 2 & St. Bagendit & 2,45 & $\mathrm{e}$ & $183,4 \quad \mathrm{a}$ & 16,4 & $\mathrm{~b}$ & 91,79 & $\mathrm{a}$ \\
\hline 3 & Inpari-10 & 2,68 & $\mathrm{~b}$ & $90,4 \quad d$ & 9,6 & $\mathrm{c}$ & 90,40 & $\mathrm{~d}$ \\
\hline 4 & Inpari-7 & 2,81 & $\mathrm{a}$ & $87,4 \quad d$ & 7,2 & $\mathrm{c}$ & 92,39 & d \\
\hline 5 & Silugonggo & 2,50 & $d$ & $76,8 \quad \mathrm{~d}$ & 28,0 & $\mathrm{a}$ & 73,28 & d \\
\hline 6 & Inpari-13 & 2,53 & $\mathrm{c}$ & $155,4 \quad b$ & 23,2 & $\mathrm{a}$ & 87,01 & $b$ \\
\hline
\end{tabular}

Keterangan: angka-angka yang diikuti oleh huruf yang berbeda menandakan perbedaan yang nyata

penelitian Imaningsih (2006), varietas padi sawah dan padi gogo memiliki perbedaan pada sifat-sifat ketahanan struktural terhadap kekeringan antara padi Sawah dan padi Gogo yang ditandai dengan perbedaan susunan anatomi daun yaitu tebal daun, tebal kutikula, dan jumlah stomata. Varietas padi Gogo memiliki daun lebih tebal, kutikula lebih tebal, jumlah stomata lebih sedikit, dan jumlah sel motor tiap deret lebih banyak jika dibandingkan dengan padi Sawah. Sebagai ciri tahan terhadap kekeringan dimana padi Gogo lebih tahan dari padi Sawah.

Ciherang merupakan varietas yang telah berhasil menggantikan IR-64. Selain rasanya yang hampir menyerupai IR-64, potensi hasilnya dapat melebihi IR-64. Berdasarkan hasil penelitian Permana (2010), potensi hasil Ciherang di Kabupaten Sukabumi sebesar 6,32 ton/ha sedangkan IR-64 5,52 ton/ha. Nurhati et al. (2008) mengatakan bahwa pada tahun 2004, varietas Ciherang menggeser dominasi varietas IR64 dan terus berlanjut sampai saat ini. Beberapa varietas unggul yang baru dilepas seperti Cigeulis, Situ Bagendit, dan Mekongga mulai diminati petani dan berkembang di Kabupaten Subang, Indramayu, Purwakarta, Cianjur, dan Tasikmalaya.

\section{KESIMPULAN}

Keenam varietas yang dievaluasi menunjukkan perbedaan nyata pada karakter tinggi tanaman, jumlah anakan produktif/rumpun, jumlah bulir bernas/malai, jumlah bulir hampa/malai, bobot 100 biji, dan GKP, sedangkan karakter BWD tidak berbeda nyata. Silugonggo memiliki umur paling genjah namun tidak tahan terhadap serangan WBC (hampir mengalami gagal panen). Hasil GKP paling tinggi dimiliki varietas $S t$. Bagendit $(8,10$ ton/ha) diikuti Ciherang ( 8,08 ton/ha), Inpari-13 (8,07 ton/ha). Inpari-7 memiliki hasil GKP 7,52 ton/ha, Inpari -10 6,71 ton/ha, dan Silugonggo 2,05 ton/ha.

\section{UCAPAN TERIMAKASIH}

Ucapan terimakasih kami ucapkan pula pada Tim SLPTT dari BPTP Jawa Barat yang telah melaksanakan kegiatan SLPTT di Kabupaten Karawang serta penyuluh BP3K Jayakerta dan petani kooperator yang telah berkenan bekerjasama untuk penyelenggaraan kegiatan ini.

Tabel 4. Umur berbunga, umur panen, persentase kadar air, dan gabah kering panen

\begin{tabular}{ccccc}
\hline No. & Varietas & Umur panen (HSS) & Kadar air $(\%)$ & GKP (ton/ha) \\
\hline 1 & Ciherang & 95 & 24,23 & 8,08 \\
2 & St. Bagendit & 88 & 24,00 & 8,10 \\
3 & Inpari-10 & 90 & 23,07 & 6,71 \\
4 & Inpari-7 & 90 & 25,37 & 7,52 \\
5 & Silugonggo & 85 & 21,80 & 2,05 \\
6 & Inpari-13 & 90 & 21,58 & 8,07 \\
\hline
\end{tabular}

Keterangan: HSS : hari setelah semai, KA : kadar air, GKP: gabah kering panen 


\section{DAFTAR PUSTAKA}

Balai Besar Penelitian Padi. 2006. Bagan warna daun, menghemat penggunaan pupuk $N$. Sukamandi. Badan Penelitian dan Pengembangan Pertanian. Kementerian Pertanian. Jakarta.

Balai Besar Penelitian Padi. 2015. Deskripsi varietas unggul baru padi. Badan Penelitian dan Pengembangan Pertanian. Kementerian Pertanian. Jakarta.

Baehaki, S.E. 2012. Perkembangan biotipe hama wereng coklat pada tanaman padi. J. IPTEK Tanaman Pangan. Vol.7 No 1: 8-17.

Baehaki, S.E. 2013. Hama penggerek batang padi dan teknologi pengendalian. J. IPTEK Tanaman Pangan. Vol. 8 No 1: 1-14.

Effedi, B. 2006. Mengatasi kekurangan produksi padi melalui PHT. Pustaka Litbang. Kementerian Pertanian. http://pustaka. litbang.deptan.go.id/bppi/lengkap/st0507061.pdf. diakses 20 Desember 2014.

Imaningsih, W. 2006. Studi banding sifat ketahanan struktural terhadap kekeringan antara varietas padi sawah dan padi gogo berdasarkan struktur anatomi daun. J. Bio-scientiae. 3 (1): 47 - 56.

Kementrian Pertanian. 2009. Rancangan Rencana Strategis Kementerian Pertanian Tahun 2010 - 2014. Jakarta. 184 hal.

Nurhati, I., S. Ramdhaniati, N. Zuraida. 2008. Peranan dan Dominasi Varietas Unggul Baru dalam Peningkatan Produksi Padi di Jawa Barat. Buletin Plasma Nutfah. 14(1): 8-13.

Peng, S., K. G. Cassman, S.S. Virmani, J. Sheehy, G.S. Khush. 1999. Yield potential trends of tropical rice since the release of IR8 and the challenges of increasing rice yield potential. Crop Sci. 39: 1552-1559.

Permana, D. H. 2010. Keragaan galur harapan padi sawah tipe baru di Sukabumi dalam rangka uji multi lokasi. Skripsi. Departemen Agronomi dan Hortikultura Fakultas Pertanian, Institut Pertanian Bogor.

Pramudyawardhana, E.F. B. Suprihatno, dan M.J. Mejaya. 2014. Potensi hasil galur harapan padi sawah ultra genjah dan sangat genjah. J. Penelitian Pertanian Tanaman Pangan, Vol. 34. No. 1: 1-12.

Rohaeni, W.R dan K. Permadi. 2013. T-test and correlation analysis of characters rice field on local probiotic microbes application Prosiding International Seminar "Technology innovation for increasing rice production and conserving environment under global climate change. Book 2. ICRR.

Setyorini, D., Kasmiati, A. Krismawati, Robi'in. 2010. Keragaan beberapa varietas unggul baru padi sistem gogo sistem tanam gogo rancah Kabupaten Probolinggo. Balai Pengkajian Teknologi Pertanian jawa Timur. http://jatim.litbang.deptan.go.id. diakses 29 Nopember 2011.

Sumarno. 2007. Teknologi revolusi hijau lestari untuk ketahanan pangan nasional di masa depan. J. IPTEK Tanaman Pangan. 2(2): 131-153.

Sutaryo, B., A. Purwantoro, Nasrullah. 2003. Heterosis standar hasil gabah dan analisis lintasan beberapa kombinasi persilangan padi pada tanah berpengairan teknis. $J$. Ilmu Pertanian. 10(2): 70-78.

Toha, H.M dan A.A Daradjat. 2008. Keragaan varietas unggul dan galur harapan padi pada budidaya padi gogo dan sawah. Prosiding Seminar Nasional Padi 2008. 645665. 